\title{
Comparison of Different Phenotypic Methods for Detection of Vancomycin Drug Resistance in Enterococcus Species
}

\author{
Deepa Pramod Devhare ${ }^{1}$, Sae Pol $^{2}$ \\ ${ }^{1}$ Assistant Professor, Department of Microbiology, Bharati Vidyapeeth Medical College, Pune. \\ ${ }^{2}$ Associate Professor, B.J. Govt. Medical College, Pune.
}

Corresponding Author: Deepa Pramod Devhare

\begin{abstract}
Introduction: Vancomycin resistant enterococci have emerged as an important cause of nosocomial infection worldwide. Vancomycin drug resistance needs to be detected accurately in all Enterococcus species in order to prevent its spread in health care setting. Present study was conducted to compare three different phenotypic methods for detection of vancomycin resistance in enterococci.

Material and methods: Study was conducted in a tertiary care hospital over a period of one year. Enterococcus species isolated from clinical samples like urine, pus, blood and sterile body fluids were tested by three different methods namely disk diffusion, E-strip and Phoenix automated system for detection of vancomycin resistance.

Results: 400 Enterococcus species were isolated from clinical samples. 19(4.8\%) Enterococcus species were found to be vancomycin resistant and one $(0.25 \%)$ strain was found to be intermediate resistant to vancomycin by all three methods resulting in $100 \%$ sensitivity and $100 \%$ specificity.

Conclusion: Present study recommends vancomycin disk diffusion as screening and Estrip as good confirmatory tests in resource poor settings for detection of vancomycin drug resistance.
\end{abstract}

Key words: VRE, vancomycin, disk diffusion, E strip, Phoenix automated system

\section{INTRODUCTION}

Enterococci constitute the normal gastrointestinal flora. Predominantly isolated species of enterococcus from clinical samples are Enterococcus faecium and Enterococcus faecalis. Other species like E. casseliflavus,, E. durans, E. raffinosus, E. gallinarum, and E. avium are found less frequently associated with clinical infections. Urine, blood, wound, pus sample, sterile body fluids are the most common clinical samples from which Enterococcus species is being isolated..$^{1-4}$ Enterococcus exhibits intrinsic resistance against most of the routinely used antibiotics like cotrimoxazole, clindamycin, cephalosporins, and low level resistance towards aminoglycosides. Enterococcus species has high tendency to acquire resistance against most of the antibiotics which includes penicillins, fluoroquinolones, erythromycin, high level aminoglycoside resistance, tetracycline, by genetic transfer of resistance genes and other drug resistance mechanisms.

Among all antibiotics glycopeptide resistance has emerged as a significant problem in healthcare settings by causing major nosocomial outbreaks. Prevalence of vancomycin resistant enterococci (VRE) has increased all over world since its first detection in England in $1988.66,7$ Vancomycin drug resistance needs to be detected accurately in healthcare settings in order to prevent large outbreaks as vancomycin drug resistance is acquired transferrable resistance. ${ }^{\mathbf{8} 9}$ Even if a single case of VRE is detected in hospital setting 
all Enterococcus species isolated from clinical samples should be screened for vancomycin resistance. 49. For accurate detection of VRE, antibiotic susceptibility tests with high sensitivity and specificity should be used to avoid underestimation. ${ }^{9,10}$ With this background present study was conducted to compare three different phenotypic methods for detection of vancomycin drug resistance in Enterococcus species.

\section{MATERIAL AND METHODS}

A prospective laboratory based observational study was conducted in department of Microbiology from January 2013 to December 2013 in a tertiary care hospital in Pune Maharashtra. Ethical committee approval was obtained for the study (Reference no- BMC/IEC/Pharmac/ D0313005-05).

Clinical samples like urine, pus, blood, pus, stool and sterile body fluids, received in the department of Microbiology for culture and sensitivity were included in the study. Samples were processed by standard microbiology techniques. Identification and speciation of Enterococcus species from these samples was done by conventional microbiological tests. ${ }^{\mathbf{1 , 1 1} 12}$ Enterococcus species obtained from these clinical samples were tested for vancomycin drug resistance by three different methods as follows;

\section{Kirby Bauer disc diffusion method}

In this method Vancomycin (30ug) disk (Himedia Pvt.Ltd.) were used for testing.

Lawn culture of test strain was prepared on Muller Hinton agar with 0.5
MF standard turbidity solutions. Vancomycin disk was then put on lawn culture and plates were incubated for complete 24hours. After incubation zone size for vancomycin was measured in transmitted light and then results were interpreted in the form of sensitive, intermediate resistant and resistant. ${ }^{13,14}$

\section{Vancomycin E strip (Antimicrobial gradient method)}

Commercially available vancomycin E strips (Himedia Pvt.Ltd.) were used for testing by this method. Lawn culture of test strain was prepared on Muller Hinton agar with $0.5 \mathrm{MF}$ standard turbidity solutions. Vancomycin E strip was placed on the surface of lawn culture incubated for 24 hours. Elliptical shape zone of inhibition was obtained after overnight incubation. Point of intersection of lower tip of ellipse with the e strip was considered the minimum inhibitory concentration (MIC) for vancomycin. ${ }^{13,14}$

\section{Phoenix automated system by BD diagnostics (Micro broth dilution method)}

It is a fully automated Microbiology system for identification and antimicrobial susceptibility testing of bacteria. As per instructions of manufacturer PMIC panel was used for performing antimicrobial sensitivity testing for Enterococcus species. 13,14

ATCC E.fecalis 29212 was used as quality control strain for all three methods for antimicrobial susceptibility testing. Results of sensitivity were interpreted as shown in Table 1.

Table 1. Interpretation of vancomycin sensitivity

\begin{tabular}{|l|l|l|l|}
\hline & Sensitive (S) & Intermediate resistant (IR) & Resistant (R) \\
\hline Vancomycin Disk diffusion & $>17 \mathrm{~mm}$ & $15-16 \mathrm{~mm}$ & $<=14 \mathrm{~mm}$ \\
\hline Vancomycin E strip & $<=4 \mathrm{ug} / \mathrm{ml}$ & $8-16 \mathrm{ug} / \mathrm{ml}$ & $>=32 \mathrm{ug} / \mathrm{ml}$ \\
\hline Phoenix system & $<=4 \mathrm{ug} / \mathrm{ml}$ & $8-16 \mathrm{ug} / \mathrm{ml}$ & $>=32 \mathrm{ug} / \mathrm{ml}$ \\
\hline
\end{tabular}

\section{RESULTS}

In present study, total 400 strains of Enterococcus species were isolated from clinical samples over a period of one year. Out of these 400 isolates, nineteen $(4.8 \%)$ isolates were found to be resistant to vancomycin by disk diffusion method and one $(0.25 \%)$ isolate was found to be intermediate resistant. (Table 2) By conventional identification methods all the 
isolates of Enterococcus species were identified as E. faecium

By vancomycin E strip method and Phoenix system, $19(4.8 \%)$ out of 400 isolates of Enterococcus species were found to be resistant and one isolate was found to be intermediate resistant. MIC range obtained for vancomycin resistant strains by
E strip method was from 32 to $256 \mathrm{ug} / \mathrm{ml}$. (Table 2). Phoenix system showed MIC of $>=32 \mathrm{ug} / \mathrm{ml}$ for all vancomycin resistant strains of Enterococcus species. For vancomycin intermediate strain MIC obtained was $8 \mathrm{ug} / \mathrm{ml}$ by both E strip and Phoenix automated system.

Table 2: Vancomycin drug resistance by different method

\begin{tabular}{|c|c|c|c|c|c|c|c|c|c|}
\hline & \multicolumn{3}{|c|}{ Vancomycin disk diffusion $(n=400)$} & \multicolumn{3}{|c|}{$\begin{array}{l}\text { Vancomycin E strip } \\
(\mathbf{n = 2 0})\end{array}$} & \multicolumn{3}{|c|}{$\begin{array}{l}\text { Phoenix automated system } \\
(\mathbf{n}=20)\end{array}$} \\
\hline & $\mathbf{S}(\%)$ & $\operatorname{IR}(\%)$ & $\mathbf{R}(\%)$ & $\mathbf{S}(\%)$ & $\operatorname{IR}(\%)$ & $\mathbf{R}(\%)$ & S(\%) & $\operatorname{IR}(\%)$ & $\mathbf{R}(\%)$ \\
\hline Enterococcus species & $\begin{array}{l}380 \\
(95)\end{array}$ & $\begin{array}{l}1 \\
(0.25)\end{array}$ & $19(4.8)$ & NA & $\begin{array}{l}1 \\
(0.25)\end{array}$ & $\begin{array}{l}19 \\
(4.8)\end{array}$ & NA & $\begin{array}{l}1 \\
(0.25)\end{array}$ & $\begin{array}{l}19 \\
(4.8)\end{array}$ \\
\hline
\end{tabular}

\section{DISCUSSION}

There are different methods described in literature for detection of vancomycin drug resistance in Enterococcus species. ${ }^{15-17}$ In present study we compared three different antibiotic susceptibility tests based on three different principles namely disk diffusion, antimicrobial gradient (diffusion-dilution), micro broth dilution method (Phoenix system).

Vancomycin resistance was correctly detected by all three methods in all 19 isolates of VRE. One strain with intermediate resistance was also accurately detected by all three methods. All three methods viz. disk diffusion, E strip and micro broth dilution method (Phoenix system) showed $100 \%$ correlation in detection of vancomycin drug resistance in Enteroccus species with $100 \%$ sensitivity and specificity. Some studies have shown that many vancomycin resistance detection systems, sometimes misclassify vancomycin resistant strains as vancomycin intermediate resistant, which is not in comparison with present study. ${ }^{1,18}$ Based on the findings of the present study disk diffusion can be used as good screening test for detection of vancomycin drug resistance especially in resource poor settings.

The E-test is considered as rapid test which is easy to perform, interpret. It is combination of disk diffusion and agar dilution method. Therefore results obtained by this method are highly correlated with results of agar and broth dilution methods. ${ }^{15,19,20}$ E strip method and Phoenix system give us MIC values for vancomycin, which are important from therapeutic point of view. These tests should be considered as confirmatory tests for vancomycin drug resistance detection. The only concerned regarding E strip and Phoenix system is cost for the test. ${ }^{14}$

\section{CONCLUSION}

Present study showed $100 \%$ correlation between disk diffusion, E-strip and phoenix automated system for detection of vancomycin drug resistance. Present study recommends disk diffusion agar as a good screening test and E-strip as good confirmatory test for detection of VRE in resource poor settings.

\section{DECLARATIONS}

Acknowledgments: Mrs. Varsha Pendse for her technical support.

Conflict of interest: The author declares that there is no conflict of interest.

Authors' contribution: All the authors have made substantial, direct and intellectual contribution to the work.

Funding: None.

Ethics statement: The study was approved by the institutional ethics committee of B.J. Govt. Medical College, Pune with protocol reference numberBMC/IEC/Pharmac/D0313005-05 and was carried out in accordance with the approved guidelines. 


\section{REFERENCES}

1. Cetinkaya Y, Falk P, Mayhall G. Vancomycin-Resistant Enterococci. Clin Microbiol Rev. 2000;13(4):686-707.

2. Pintado V, Cabellos C, Moreno S, Meseguer A, Ayats J, Viladrich P. Enterococcal meningitis: a clinical study of 39 cases and review of the literature. Med Balt. 2003;82(5):346-64.

3. Han D, Wisniewski S, Wilson L, Barza M, Vine A, Doft B, et al. Spectrum and susceptibilities of microbiologic isolates in the Endophalmitis Vitrectomy Study. Am J Ophthalmol. 1996;122(1):1-17.

4. Barie P, Christou N, Dellinger E, Rout W, Stone H, Waymack J. Pathogenicity of the Enterococcus in surgical infections. Ann Surg. 1990;212(2):1559.

5. Murray B. The life and times of the Enterococcus. Clin Microbiol Rev. 1990; 3(1):46-65.

6. Ingerman M, Santoro J. Vancomycin: a new old agent. Infect Clin North Am. 1989;3:641-51.

7. Uttley A, Collins C, Naidoo J, George R. Vancomycin resistant enterococci. Lancet. 1988;i:57-8.

8. Cattoir V, Leclerq R. Twenty-five years of shared life with vancomycin-resistant enterococci: is it time to divorce? J Antimicrob Chemother. 2013;68(4): 731-42.

9. DeLisle S, Perl T. VancomycinResistant Enterococci: A Road Map on How To Present the Emergence and Transmission of Antimicrobial Resistance. Chest. 2003;123:504S-518S.

10. Swenson J, Clark N, Ferraro M, Sahm D, Doem G, Pfaller M, et al. Development of a standardized screening method for detection of vancomycin-resistant enterococci. J Clin Microbiol. 1994;32(7):1700-4.

11. Koneman EW, Allen SD, Janda WM, Schreckenberger PC, Winn WC, editors. Gram-positive cocci Part 2: Streptococci, Enterococci and the Streptococcus like bacteria. In: Colour Atlas and Text Book of Diagnostic
Microbiology. $\quad 6^{\text {th }}$ ed. Philadelphia: Lippincott; 2006. p. 725-33.

12. Betty AF, Daniel LS, Weissfeld AS, editors. Overview of bacterial identifications methods and strategies. In: Bailey \& Scott's Diagnostic Microbiology. $12^{\text {th }}$ ed. Missouri: Mosby Elsevier; 2007. p. 216-41.

13. Clinical and Laboratory Standards Institute.Performance Standards for Antimicrobial Susceptibility Testing; Twenty-Second Informational Supplement. M100-S22. 2012;32(3).

14. Jorgensen J, Ferraro M. Antimicrobial Susceptibility Testing: A Review of General Principles and Contemporary Practices. Medical microbiology CID 2009:49 (1 december) : 1749.

15. Kobayashi I, Muraoka H, Iyoda T, Nishida M, Hasegawa M, Yamaguchi K, et al. Antimicrobial susceptibility testing of vancomycin-resistant Enterococcus by the VITEK 2 system, and comparison with two NCCLS reference methods. J Med Microbiol. 2004;53(12):1229-32.

16. Biswas P, Dey S, Adhikari L, Sen A. Detection of vancomycin resistance in enterococcus species isolated from clinical samples and feces of colonized patients by phenotypic and genotypic methods. Indian $\mathbf{J}$ Pathol Microbiol. 2016;59(2):188-93.

17. Bobenchik AM, Hindler JA, Giltner CL, Saeki S, Humphries RM, Carroll KC. Performance of Vitek 2 for Antimicrobial Susceptibility Testing of Staphylococcus spp. and Enterococcus spp. J Clin Microbiol. 2014;52(2):3927.

18. Pendle S, Jelfs P, Olma T, Su Y, Gilroy N, Gilbert GL. Difficulties in detection and identification of Enterococcus faecium with low-level inducible resistance to vancomycin, during a hospital outbreak. Clin Microbiol Infect. 2008;14(9):853-7.

19. Tenover F, Swenson J, O'Hara C, Stocker S. Ability of commercial and reference antimicrobial susceptibility testing methods to detect vancomycin 
Deepa Pramod Devhare et.al. Comparison of different phenotypic methods for detection of vancomycin drug resistance in enterococcus species.

resistance in enterococci. J Clin Microbiol. 1995;33(6):1524-7. 51.

20. Klare I, Fleige C, Geringer U, Witte W, Werner G. Performance of three chromogenic VRE screening agars, two Etest ${ }^{\circledR}$ vancomycin protocols, and different microdilution methods in detecting vanB genotype Enterococcus faecium with varying vancomycin
MICs. Diagn Microbiol Infect Dis. 2012;74(2):171-6.

How to cite this article: Devhare DP, Pol S. Comparison of different phenotypic methods for detection of vancomycin drug resistance in enterococcus species. International Journal of Research and Review. 2021; 8(9): 289-293. DOI: https://doi.org/10.52403/ijrr.20210939 